\title{
Entrevista
}




\section{Karl-Otto Apel: a raiz comum entre ética e linguagem}

\section{JESUS DE PAULA ASSIS}

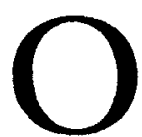

filósofo alemáo Karl-Otto Apel esteve no Brasil para uma série de confcrências - especialmente no Departamento de Filosofia da Universidade de São Paulo - , durante o mês de outubro de 1990. Foi sua primeira viagem intelectual ao Brasil. Na primeira, visitou apenas as cataratas de Iguaçu. Ligado à Escola de Frankfurt é, ao lado de Jürgen Habermas, seu maior expoente em atividade.

Apel dissc que, ainda em 1990, deveria tornar-se Professor Emérito pela Universidade de Frankfurt. Embora não fosse mais obrigado a dar aulas, pretendia continuar suas atividades docentes e de pesquisa. Definiu sua área de estudo como "semiótica pragmática transcendental" . Contra o relativismo que prevalece na filosofia que se estuda hoje, Apel levanta questổes sobre valores transcendentes que possibilitam a própria experiência humana e que não podem - ao contrário do que defendem relativistas na linha do segundo Wittgenstein - estar inteiramente sujeitos a condiçóes locais e históricas.

Apel nos recebeu no hotel em que esteve hospedado, em Sáo Paulo. Parte da entrevista que segue foi publicada no suplemento "Letras", da Folba de S. Paulo, em 10 de novembro de 1990.

$$
\text { * }
$$
Brasil?

Jesus de Paula Assis - Qual foi o assunto de suas conferências no

Apel - Apresentei ao público duas opçóes: ética ou semiótica transcendental como filosofia primeira (minha área específica de trabalho). A cscollha recaiu sobre a última. $O$ título completo das conferências foi Semiótica transcendental e os paradigmas da filosofia.

$J P A$ - O sr. trabalha com metodologia das ciências sociais.

$$
\text { Apel - É isso. }
$$


$J P A$ - Gostaria de começar com uma definição de sociologia dada por Max Weber: "É a ciência que se ocupa da compreensão interpretativa da açâo social e, ligado a isso, com a explicação causal de seu curso e conseqüências". Essa definição coloca dois métodos, o causal que é distintivo das ciências naturais - e o interpretativo - que é característico das ciências humanas - lado a lado, sem deixar claro como ambos se articulariam. $\mathrm{O}$ sr. poderia falar um pouco dessa tensão metodológica?

Apel - Toda minha vida insisti na diferença metodológica entre ciências naturais e humanidades. Escrevi muito sobre o assunto, e mesmo um livro sobre a controvérsia explicação/compreensão. No livro, traço toda a história desde seu início, no século passado na Alemanha, até hoje, depois de Wittgenstein. $O$ assunto se tornou muito complexo e é difícil sumariar a questão toda. Hoje, a questão já não é apenas a distinção entre explicação e compreensão, tal como foi introduzida por Droysen e Dilthey. Max Weber recebeu essa tradiçăo, mas insistiu na importância para a sociologia dos métodos de explicação como métodos de controle, o que torna a coisa toda muito complicada. O principal ponto que devemos introduzir aqui é que não se tem apenas um método nas ciências sociais. Temos, isto sim, diferentes tipos de ciências sociais. Escrevi sobre esses diferentes tipos, que variam conforme o interesse cognitivo que se tenha. Por exemplo, posso falar de uma distinção muito forte: é muito diferente a situação na qual estou interessado em conseguir conhecimento preditivo - para tentar controlar o comportamento humano através de explicaçóes nomológicas, o que pode ser usado no campo da tecnologia social - daquela em que me interesso primariamente em reconstrução hermenêutica. Cito como exemplo a história da ciência. História da ciência não tem nada a ver com explicação nomológica. Seria absurdo perguntar coisas como "por quê?" - em termos de leis e condiçóes antecedentes - para saber o que teria de acontecer para que Newton introduzisse seus conceitos fundamentais sobre espaço e tempo absolutos. Se eu colocar aqui uma questão do tipo "por quế?" ("por que ele fez isso?" - eu poderia dizer: "por que Mozart compôs suas óperas?"), tenho em mente coisas bem diferentes do que no caso em que procuro explicaçóes nomológicas nas quais pergunto "por quê?" em termos de "que causas?", em termos de condiçóes antecedentes e condiçóes nomológicas que tiveram de valer para que o evento em questão ocorresse. Nesse sentido, nunca posso formular tal pergunta nas humanidades. Acho estranho, ou até irônico, que precisamente a história da ciência, por exemplo, história das ciências exatas, náo possa ser uma ciência. É parte das humanidades, e deve responder a questốes que peçam por razóes, e não por causas. Deve, portanto, apoiar-se em compreensão, 
interpretação e nos métodos das ciências humanas.

$J P A$ - O sr., portanto, discorda da visão de, por exemplo, Hempel, colocada em $A$ função das leis gerais em história, de que, no fim de contas, a história nāo é (ou não deveria ser) diferente metodologicamente das ciências humanas?

Apel - Sempre discordei de Hempel. Vou mais longe. No ponto atual das discussóes, o esquema de explicação de Hempel/Oppenheim, ou o esquema de Popper, não funciona sequer nas próprias ciências naturais. E muito importante sublinhar, antes de entrar em detalhes técnicos relativos às ciências humanas: esse esquema de explicação não é relevante nem mesmo nas ciências naturais. $\mathrm{O}$ modelo - que nos anos 30 era compartilhado por Popper, Hempel e seus seguidores - dizia que a explicação podia ser entendida como uma espécie de dedução (dedução do explanandum - o que deve ser explicado - a partir do explanans - as condiçóes que explicam), sendo o explanans, constituído de leis e condiçóes antecedentes. Assim, a estrutura lógica da explicação seria a mesma da predição. Acho que isso é completamente superficial e falso. Acho que Peirce sempre teve uma definição muito melhor de explicação nas ciências naturais. Para ele, explicação nas ciências naturais não era dedução do explanandum a partir do explanans, mas sim o achar de um explanans a partir do qual fosse possível deduzir o explanandum, no caso de uma explicação causal. Fica claro que, na explicação causal, apenas parte da explicação tem estrutura dedutiva. Mas a parte mais importante é encontrar o explanans a partir do qual se possa deduzir o explanandum. Fazer isso requer uma inferência sintética, o que Peirce chamava inferência abdutiva. E essa é a parte realmente criativa, inovadora, onde os cientistas têm de criar um tipo novo de conhecimento sintético. Não é apenas indução, mas também abdução. Abdução é o passo mais importante no desenvolvimento do conhecimento. Por isso, é importante diferenciar entre o modelo de Hempel/Oppenheim (e o primeiro modelo de Popper) do modelo de Peirce para explicação nas ciências naturais, porque isso mostra que a estrutura da explicação não é exatamente a mesma da predição. Você conhece o exemplo de Hempel sobre o carro (o radiador de um automóvel estoura numa noite fria; o evento pode ser explicado em termos de leis físicas conhecidas - por exemplo, "a água aumenta de volume quando congela" - e de condições antecedentes do tipo "o radiador estava cheio e tampado", "ontem fez muito frio", etc.). Esse famoso exemplo é completamente equivocado. Ele pressupóe a principal característica da explicação, ou seja, que você já tem o explanans de onde pode deduzir o explanandum, da mesma forma que alguém é capaz de predizer alguma coisa. Mas esse é o caso somente quan- 
do nāo há ciência inovadora, quando você tem apenas uma ocorrência em mãos e a deduz a partir do que já é sabido. Na ciência real, o problema é bem outro. O problema de achar uma explicação é o de achar um novo explanans, encontrar novas hipóteses de leis, fazer novas hipóteses nomológicas. Não é o caso de apenas achar novas condiçóes antecedentes. Existe um passo abdutivo, uma conquista sintética. Se se levar isso em consideração - e eu sou um peirceano, não só aí, mas também em outros aspectos -, então a questão se torna: "Quais as dificuldades para se encontrar o que equivalha a explicaçóes nas ciências humanas e nas ciências naturais?" . Agora, entro com minhas idéias - e de Habermas - acerca de diferenças de interesse cognitivo. Primeiro, coloco que existe uma diferença de interesse cognitivo entre as ciências naturais típicas (que estão interessadas em explicação causal, nomológica ou estatística) $\mathrm{e}$ as ciências hermenêuticas, as humanidades. Mas, de novo, eu diria que, dentro do espectro das ciências sociais, existem questóes muito diferentes, de acordo com interesses cognitivos muito diferentes. De novo, existe um tipo de ciência social que está muito próximo das ciências naturais e da tecnologia. Por exemplo, as ciências do comportamento, onde se quer, em muitos casos, explicar o comportamento de consumidores, ou de votantes, e se tenta tratar os seres humanos como porçóes da natureza. Isso nunca é realmente possível, mas se tenta encontrar qual seria o comportamento médio de uma amostra e que prediçóes seria possível fazer. É claro que existe um grande interesse em tecnologia social no sentido de se ter um certo tipo de controle sobre seres humanos, como se eles fossem objetos das ciências naturais. Mas isso não é possível completamente. Sabemos que existem coisas como a autocontradição. Isso nunca acontece com porçóes da natureza. Mas, no caso das ciências sociais, os objetos são parceiros de comunicaçáo e se eles têm conhecimento acerca de o que o cientista sabe sobre eles, entáo eles intervêm com suas próprias decisóes e podem produzir autocontradiçóes, coisa que nunca aconteceria em ciências puramente naturais. É somente esse tipo de ciência social que está próximo das ciências naturais, e pode ser estilizado com um método estatístico nomológico, etc. E tem trazido alguns resultados. Mas é muito diferente das humanidades típicas, ciências puramente hermenêuticas, como por exemplo história da ciência ou história da cultura como um todo. Aqui, existem questóes de tipo radicalmente diferente. Não pergunto, quando quero saber "como isso foi acontecer?" por causas e leis. Isso seria absurdo. Pergunto "por que razóes eles fizeram isso?" . Razóes que podem ser boas ou ruins. Assim, graus entram em cena. Por exemplo, é muito irônico que pessoas como Karl Popper, que antes eram a favor de ciência social neutra em termos de valores (como o era Max Weber), tenham, depois, chegado a um 
ponto de vista completamente distinto. Na controvérsia com Thomas Kuhn, e temendo o perigo do relativismo, Popper tornou-se atento à problemática da história da ciência. Notou que ela fazia parte das humanidades e, assim, nāo era neutra em termos de valores. Para reconstruir a história da ciência era preciso recorrer a conceitos como boa e má ciência. O discípulo de Popper, Imre Lakatos, postulou a distinçấo entre história interna e externa da ciência. Primciro, era preciso reconstruir a história da ciência do ponto de vista interno. Depois, num outro passo, seria possível procurar por uma reconstruçáo externa, mas apenas quando a reconstrução interna já não fosse possível. Você tem aí uma distinção bem evidente, que deixa clara a parte hermenêutica, a qual não é neutra, tem valores e pretende entender e avaliar a história da boa ciência. Essa história é um processo no qual existe progresso. A transição para a reconstrução externa só acontece se necessário. Lakatos formulou seu princípio assim: "reconstrução interna tanto quanto possível". E isso é precisamente o princípio de Gadamer de "antecipação da perfeição" na interpretação hermenêutica. Esse é também o princípio de caridade em Quine e Hanson. É um princípio hermenêutico o de que devemos tentar compreender e avaliar de forma positiva tanto quanto for possível. Só se isso não for possível é que fazemos a transiçāo.

JPA - Nessa fronteira, como (e quem) decide quando é hora de tentar a transição?

Apel - Primeiro é preciso tentar uma compreensão hermenêutica. Primeiro avaliar positivamente tanto quanto possível. Por exemplo, se em nossa conversa você diz algo novo, primeiro devo tentar entender tanto quanto possível, não apenas o que você quer dizer, mas também descobrir a plausibilidade do que você diz. Devo aprender. Mas, se vejo que há inconsistências, chego ao momento $\mathrm{cm}$ que devo tentar explicar via causas externas "o porquê desse sujeito estranho me dizer essas coisas" . O limite é atingido quando me sinto autorizado a começar a buscar uma explicaçâo externa (penso " talvez ele tenha motivos ou interesses ocultos", etc.). Essa é exatamente a atitude dos historiadores da ciência. E acho que Popper e especialmente Lakatos estão certos quando se colocam contra os que tentam fazer história da ciência apenas através de explicações externas (como os componentes da Escola de Edimburgo). Pois eles não podem sequer saber o que pertence $\mathrm{e} o$ que não pertence à ciência. Só fazendo um primeiro passo seletivo, você poderá ter uma idéia sobre o que seja boa ciência. Daí, você pode entender a história da ciência como uma peça de progresso no sentido da boa ciência. E só num segundo passo você pode passar para causas externas. Eu não estou dizendo que não haja causas externas. Se você toma a genética ou a pes- 
quisa farmacêtutica atual, existem interesses econômicos em jogo, e os cientistas certamente estão motivados por isso, ou seja, existe motivação externa, existc ambição pessoal. Náo nego isso, mas digo que, $\mathrm{cm}$ boa história da ciência, devemos primeiro ter um conceito positivo de boa ciência e de progresso em ciência e devemos tentar entender os processos da história desse ponto de vista. Só se isso chegar a um limite, teremos razōes para desistir dessa empresa hermenêutica, e estaremos intitulados a tentar uma explicaçáo externa. Esse é mais ou menos o paradigma para a relação entre métodos hermenêuticos e métodos explanatórios nas ciências humanas. Mas a coisa é ainda mais complexa. Mesmo quando estou autorizado a fazer a transiçáo da hermenêutica para a explicação externa, ainda assim estou longe da explicaçáo nas ciências naturais.

$J P A$ - O sr. fala de se ter uma idéia de o que seja boa ciência para compreender a história da ciência. Mas, depois de Thomas Kuhn, os epistemologistas dizem que o próprio conceito de o que seja boa ciência muda. Embora o modelo de Kuhn seja criticado, ele pelo menos mostra que existem ocasióes bem evidentes de descontinuidade (as revoluçóes), em que a idéia de boa ciéncia muda completamente.

Apel - É verdade. Na primeira edição de seu livro A estrutura das revoluçōes cientificas (em 1962), ele falava de incomensurabilidade entre diferentes paradigmas. As idéias de progresso e de boa ciência foram relativizadas a fases na história da ciência. Nunca me satisfiz com isso. Náo se pode negar que existam coisas como ciéncia normal, onde nem tudo está em questão e que é exatamente isso que propicia progresso. Isso é bom Wittgenstein. Náo podemos colocar tudo em questão todo o tempo, questionar e duvidar de tudo. Essa idéia supera Popper. Para ter progresso, é preciso pressupor algum tipo de certeza paradigmática que não é posta em dúvida. Kuhn detecta isso muito bem, num sentido bem wittgensteiniano. Mas ele vai longe demais - ou, pelo menos, ia quando afirma que a transição de um paradigma para outro é apenas conversão (no sentido de conversão religiosa), que não existe transição racional, que náo existe idéia de progresso que perpasse todas as fases da ciência. Por exemplo, eu diria que Kuhn não estava errado, mas um pouco equivocado, quando dizia que a transiçáo entre física aristotélica e física moderna foi uma transição de paradigma como a transição entre flogisto e a teoria de Lavoisier. Porque entre Aristóteles e Galileu (ou Newton) houve uma mudança realmente muito profunda, que é muito mais que uma transição de paradigma dentro da física moderna. Existiu lá uma transição de interesse cognitivo. A física aristotélica tinha interesses teleológicos e não apenas de controle isento de valores sobre os fatos, como acontece na ciência moderna. Náo cra física a serviço do 
controle do mundo. Na ciência moderna, esse é um pressuposto pragmático transcendental característico, e muito diferente de Aristóteles. É incorreto chamar tudo isso de transiçáo de paradigmas. A transição a partir de Aristóteles é uma transição de interesse cognitivo. Trata-se de outro tipo de ciência. Dentro da ciência moderna, existem muitas pressuposiçóes que permanecem constantes. Nunca as mudamos. Desde Galileu, estamos convencidos de que deve haver, por exemplo, experimentos reproduzíveis, que possam ser repetidos por cientistas quaisquer. Isso não mudou até hoje. Independentemente de mudanças de paradigma, existem valores como a repetibilidade, conhecimento isento de valores sobre os fatos, validade intersubjetiva, os quais permitem progresso constante que se expressa mesmo no poder tecnológico, que permite a seres humanos dominar o ambiente. Isso tem sempre aumentado.

$J P A$ - Hoje em dia, idéias como reprodutibilidade são apenas critérios de regulação. Numa época de big-science, como na física de altas energias, ninguém realmente reproduz experimentos. Mesmo o contato entre teoria e observação acaba sendo posto de lado em prol de simulaçốes em computador nas quais, na verdade, teorias são testadas contra teorias e não contra a experiência. Năo precisamos, em vista disso, de novos critérios metodológicos?

Apel - É um problema novo e sério. Mas eu hesito muito em tirar a partir disso conclusóes acerca de novas metodologias. Não é possível realmente repetir todo experimento. Temos de acreditar nos outros cientistas. Mas não acho que isso seja fundamental em termos do interesse cognitivo da ciência. Hoje, o interesse cognitivo é até mais forte do que era: controle tecnológico do meio ambiente.

$J P A$ - Esse é o único interesse cognitivo das ciências naturais?

Apel - Começo com uma exceção. Você pode ter interesse cognitivo em reconstruir o processo de evolução biológica, ou mesmo evolução pré-biológica, da matéria. Essas teorias existem. Você tem entáo interesse em reconstruir a pré-história da história humana, e pode fazer ciência natural desse ponto de vista. Em detalhe, isso não é diferente dos métodos normais de explicação causal. Mas isso pode ser incorporado a um novo quadro de interesses, que é diferente do interesse de controle.

$J P A$ - Isso vale para evolução cosmológica?

Apel - Primariamente biológica. Você pode, também, ter interesses cosmológicos, mas o interesse na reconstrução da pré-história da história é dominantè. Esse interesse em cosmológia foi mesmo exercido por Peirce. Mas o ponto de maior importância é a reconstruçăo da evo- 
lução da vida como pré-história da história humana. Nisso se encaixam a etologia de Konrad Lorenz e a sociobiologia. Isso pode ser considerado um interesse similar ao que move a reconstrução de nossa história. Não se quer, aqui, ter controle sobre o comportamento, de acordo com leis, mas sim comprcender como a história pode ter ocorrido, como possam tcr evoluído os animais superiores e, destes, nós mesmos. Aqui entram

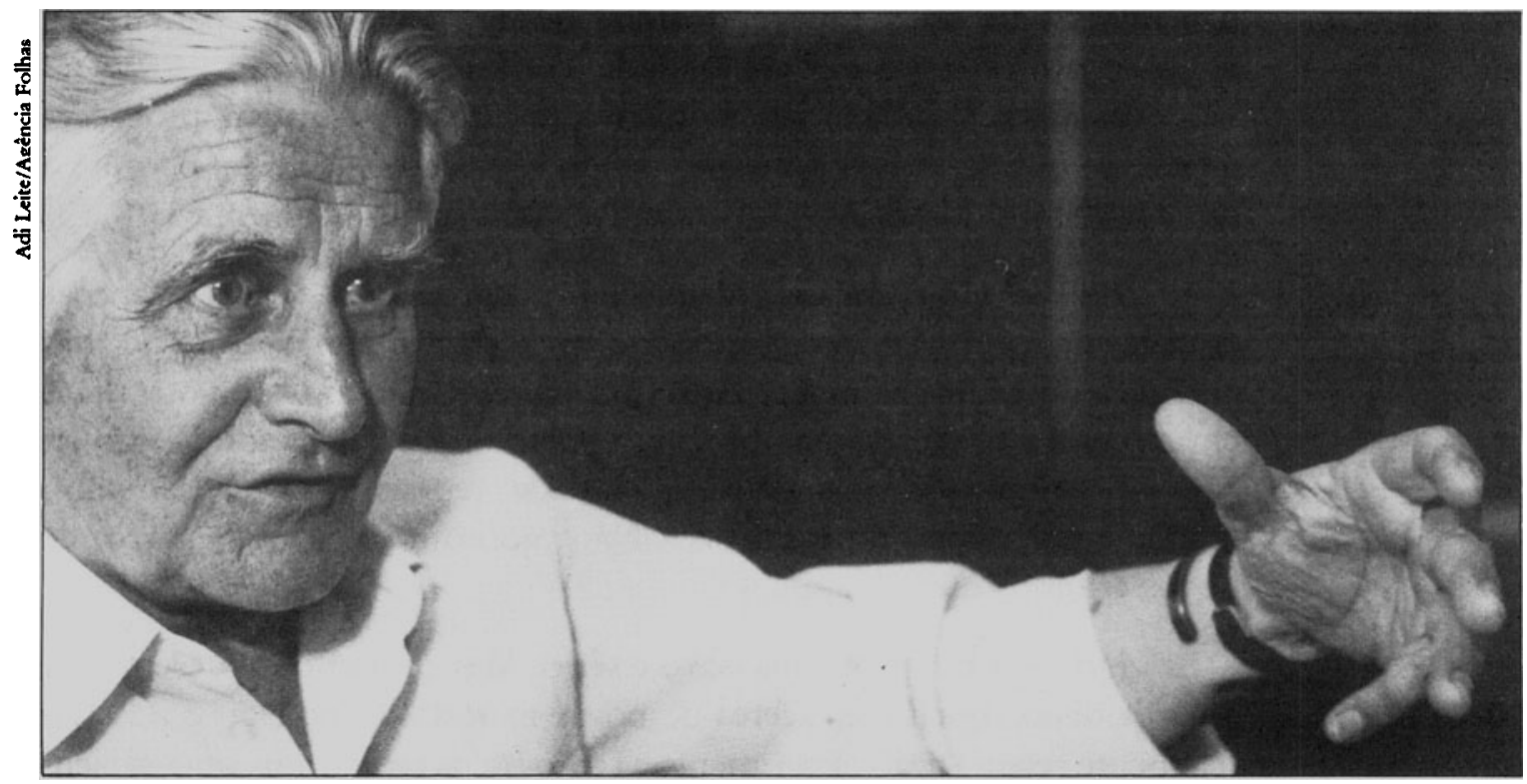

Karl-Otto Apel

em jogo interesses hermenêuticos. Se você olhar para a etologia e para a sociobiologia, verá que essas disciplinas usam várias categorias hermenêuticas quando discutem comportamento, quando falam de animais "cuidando" de sua ninhada. Isso tudo é concebido em analogia com o vocabulário sociológico. Os sociobiólogos chegam a usar - heuristicamente - conceitos de estratégia tirados da teoria dos jogos. Eles têm aplicado isso com muito sucesso ao comportamento animal. É claro que eles não defendem que os animais tenham interesses econômicos como os seres humanos. Não dizem que cada animal age estrategicamente. Mas dizem que o grupo age, o que seria favorecido pela pressão evolutiva. A evoluçáo teria favorecido àqueles animais que pudessem maximizar a proliferação de seus genes e de genes correlatos. Esse tipo de heurística é usado por Dawking ( $O$ gene egoista), por exemplo, o que tem inspiraçáo nas ciências humanas. Isso responde à sua pergunta acerca dos diferentes interesses cognitivos nas ciências naturais. Em todo caso, eu diria 
que, deixando de lado a evolução, o interesse-padrão é de dominação e de conhecimento tecnológico.

$J P A-\mathrm{E}$ esse interesse (mais próximo das ciências humanas) é o que mais interessa ao leigo hoje.

Apel - Isso tem um apelo muito grande. Mas você deve ver que toda nossa vida na sociedade industrial está baseada no controle crescente do ambiente. $O$ iinteresse tecnológico é ainda predominante.

$J P A-\mathrm{E}$ quanto aos diferentes interesses nas ciências sociais? Até agora falamos apenas de tecnologia social, que é rćlativamente próxima do interesse das ciências naturais.

Apel - Existem dois pólos. De um lado, as ciências do comportamento, mais dedutivo-nomológicas, a serviço da tecnologia social e, de outro, conhecimento através de reconstrução hermenêutica da história, como, por exemplo, na história da ciência ou da cultura em geral. Entre eles, existem muitos outros tipos. Temos também a explicação funcionalista. Por exemplo, a teoria dos sistemas sociais. Eu e Habermas não concordamos com outros autores que falam de explicaçóes funcionalistas de sistemas sociais como tudo o que existe (por exemplo, que mesmo comunicação ou moralidade podem apenas ser explicadas em termos funcionais). O máximo que podemos concordar é que esse tipo de explicação é muito importante e que deve ser tomado em consideraçáo.

$J P A$ - Essas explicaçóes dão conta do comportamento da sociedade, mas não dos agentes.

Apel - Existe uma velha tensão dentro das ciências sociais entre os-objetivos e os efeitos das açóes de pessoas individualmente e, por outro lado; os resultados no nível dos sistemas. Por exemplo, em economia, Adam Smith já reconhecia que virtudes podiam se tornar vícios em outro nível e vice-versa. Ele falava da "mão invisível" que cuidava para que o egósmo dos agentes individuais resultasse no bem-estar da sociedade. Esse é o germe do reconhecimento dessa tensão entre açáo individual e açáo da sociedade. Sabemos hoje que essa é uma tensão que não pode ser superada. Os marxistas prometiam superar isso, mostrariam que os seres humanos poderiam se organizar de modo a fazer a história. Isso é uma utopia que falhou terrivelmente. $\mathbf{E}$ agora estamos exatamente no centro dessa tensão entre a boa vontade e as boas intençóes dos agentes individuais (políticos, moralistas) e, por outro lado, as composiçóes dentro do sistema. Esse é talvẹz o maior problema das teorias sociais hoje. . 
JPA - Em vista do que ocorre no Leste europeu, o que filósofos e cientistas sociais têm a oferecer para os políticos de hoje?

Apel - O que estamos presenciando representa, também, a queda das filosofias especulativas em história, e da noção de progresso necessário em história, que veio de Hegel, de Comte e, em especial, na linha do marxismo. Isso realmente caiu. $O$ que vimos nestes dois anos é considerado um triunfo do capitalismo sobre os sistemas planificados. A idéia de planificar a sociedade, de modo que ela consiga o que precisa, de modo a que ela progrida, me parece que falhou inteiramente. Isso é o programa terrivelmente utópico do Estado marxista ortodoxo. Os intelectuais deveriam se tornar reis-filósofos, colocando a si próprios acima da sociedade, como aqueles que sabem o que é necessário fazer. O que é bom torna-se aquilo que é historicamente necessário. Existe aí a pressuposiçāo de que existem intelectuais que podem saber o que seriam os processos necessários da história. Isso tudo caiu. Mas, por outro lado, não acredito que tais acontecimentos signifiquem uma vitória do capitalismo. Isso pode ser uma ilusão. Nossos problemas apenas começam. O que temos agora é uma détente Leste/Oeste. Ótimo, mas é agora que os problemas começam e, no momento, náo temos filosofia ou programas que dêem conta desses problemas. Exemplos disso são os problemas de diálogo entre Primeiro e Terceiro mundos e a questáo ecológica que, hoje, é uma das maiores crises que enfrentamos. Temos trabalhado muito nisso em Frankfurt. Frankfurt?

$J P A$ - O senhor se considera um componente da Escola de

Apel - Não da antiga. Eu, Habermas e outros formamos uma nova escola de Frankfurt. Temos desenvolvido algumas coisas novas. Mas sou cético. Estamos ainda no início. Sua questão é pertinente: o que acontece hoje? O que temos hoje? Que teorias sociológicas ou filosóficas poderiam dar conta da situação? Sou bastante cético, embora estejamos tentando. Existem alguns enfoques novos que, talvez, possam ajudar. Em muitos lugares, aqui no Brasil, falei sobre ética do discurso. Eu acho que ética do discurso é uma saída para problemas de corresponsabilidade numa escala planetária. Isso não apenas com respeito à crise ecológica, mas também com respeito à justiça social.

$J P A$ - Como o senhor definiria essa ética?

Apel - Primeiro devo dizer que isso se liga a meu enfoque (e de Habermas) à filosofia teórica (pura) e à filosofia da ciência. Está intimamenté ligado à hermenêutica $\mathrm{e}$ às ciências sociais reconstrutivas. Ten- 
tei desenvolver o assunto, em minhas conferências, aqui, em um nível bem elementar. A noçâo está ligada a um enfoque novo da filosofia transcendental. Náo pretendo recuar até, por exemplo, uma consciência solitária, a um solipsismo do tipo "eu penso", como o que está em Descartes e em Kant ou Husserl. Acho que o a priori que não podemos evitar, que é em última instância requerido, é que sempre estamos discursando. Nunca penso solitariamente. Posso, é claro, pensar solitariamente em minha sala, mas sempre pretendo validade intersubjetiva. Assim, a estrutura de meu pensamento é sempre a estrutura de um discurso realmente argumentativo. Desenvolvi com Habermas a noçăo de que, sempre que tenho pretensóes de validade, tenho de seguir:

a. pretensão de sentido (compartilhamento de sentido com outros - com uma comunidade ilimitada de comunicação),

b. pretensão de sinceridade e, também,

c. pretensão de direito moral.

Essa é uma nova característica da ética do discurso: ela nasce do mesmo ponto em que nasce a filosofia teórica. Pois, agora, a pressuposição metodológica não é mais o "eu penso", mas o "eu argumento", pois sou membro de uma comunidade real e estou, ao mesmo tempo, antecipando estruturas de uma comunidade ideal, pois devo dirigir meus argumentos a essa sociedade. Devo supor a pretensão à verdade para todo componente dessa sociedade ideal. Quando tenho essas pressuposiçóes, contrariamente às suposiçóes de Descartes ou Kant ou Husserl, tenho também as fundações da ética. Pois não posso pensar, ter pretensōes à verdade, argumentar seriamente, sem pressupor as normas éticas fundamentais de uma sociedade ideal livre. Devo, desde o início, reconhecer que todos os componentes têm direitos iguais para perguntar, responder, etc. Eles são corresponsáveis comigo em qualquer questão relevante. Todos têm de ser iguais em termos de deveres e direitos. Assim, a ética aparece logo no início quando procuramos o que é pressuposto no estudo de teorias. Esse é o ponto principal.

$J P A$ - Mas o método solipsista insistia em que as categorias daquela forma encontradas eram realmente fundamentais. Seu enfoque não levaria a "categorias provisórias", já que discurso e comunidade mudam?

Apel - Esse é um ponto importante. Muitos dizem que, quando passo do "eu penso". para o "eu argumento", abro as portas para o relativismo e o historicismo, pois me torno dependente de uma época $\mathrm{e}$ de uma forma de vida em particular. Wittgenstein e Richard Rorty falam dessa dependência a um consenso apenas contingente, dentro de uma dada tradição. Rorty, por exemplo, diz: "sou um norte-americano e 
nunca poderei transcender essa condiçăo. Sou completamente dependente disso". O mesmo é dito por conservadores como MacIntire ("que ou qual racionalidade?", "que justiça?", etc.). Acho tudo isso completamente equivocado. Náo é porque parto do "eu argumento" que devo desistir de toda pretensão à universalidade. De um lado, reconheço que aprendemos de Wittgenstein, de Heidegger, de Collingwood, de Gadamer, que somos dependentes de uma dada tradição. Por exemplo, sendo alemâo, sou dependente de uma certa tradição européia de pensamento. Sei disso. Mas isso é uma coisa. Outra é dizer que náo sou capaz de argumentar contrafactualmente, antecipando a estrutura de uma comunidade ilimitada de comunicação. Isso não é relativizável ou histórico. Tem características universais que todos os argumentadores devem reconhecer. Você pode demonstrá-lo. Se você argumenta em favor do relativismo, então, ao mesmo tempo, está apelando para uma comunidade ideal. Quem age assim pressupóe coisas que nega, como, por exemplo, uma noção de validade universal, a existência de normas morais universais, pelo menos quando se argumenta. Nunca vi esses filósofos se comportarem de outro modo. Eles mostram, por seu comportamento nos congressos de filosofia, que, implicitamente, seguem essas normas universais. Podemos encontrar isso mesmo em Wittgenstein. Ele sempre fala de certos hábitos, formas de vida ou jogos de linguagem, mas sempre se esquece de seu próprio jogo de linguagem, que lhe permite falar de todos os outros. Não existem apenas aqueles jogos de linguagem sobre os quais ele fala, mas também o jogo de linguagem que está pressuposto quando ele fala de todos os jogos. Só os filósofos falam com essa pretensão à universalidade. E mesmo aqueles que dizem que essa pretensão é impossível. Filósofos como Rorty mostram, por seu próprio comportamento, que estáo sempre em contradição. Derrida, por exemplo, diz que não é possível compartilhar significado com outros, que existe sempre um desvio. Mas, para mostrar isso, para defender essa tese, ele deve pressupor o oposto. Ele deve escrever livros e esse ato já contradiz a tese defendida. Os pós-heideggerianos também dizem que tudo é dependente da história do ser: Tudo isso, todos esses discursos, pressupóem exatamente o que negam. Rorty, por exemplo, diz sempre "por que não desistimos de tudo e passamos a escrever novelas?". E ele diz isso em todos os congressos de filosofia. Até agora, não vi nenhuma novela de Rorty. Essa é a moda da filosofia posterior a Nietzsche. Todos os filósofos nessa linha estão enredados nesse tipo de contradiçâo.

$J P A$ - Sua argumentaçăo aponta que o relativismo tem falhas óbvias. Por que, em sua opinião, ele se tornou tão atraente na filosofia do século $\mathrm{XX}$ ? 
Apel - É compreensível que visóes sobre nossa dependência a condiçôes históricas, culturais e locais sejam impressionantes. Esse movimento é antigo. Dilthey falava disso já no século XIX, na Alemanha. Hoje, isso assumiu dimensóes planetárias. Mas, em todo lugar, as pessoas dão o passo seguinte, sem parar e refletir. E são levadas a conseqüências erradas, que não se seguem realmente dessa reflexão sobre nossa dependência a condiçōes históricas. Falta, simplesmente, um pouco de reflexão.

$J P A$ - Durante suas respostas o senhor usou várias vezes o termo "paradigma". Ele está sendo usado no mesmo sentido de Thomas Kuhn (Kuhn não o usa para falar de filosofia)?

Apel - Uso quase no sentido kuhniano e também o aplico à história da filosofia. Existem algumas partes do significado de "paradigma" que compartilho com ele, outras que não. Por exemplo, não compartilho do relativismo de Kuhn, quando ele afirma que a relaçáo entre diferentes paradigmas na história é de incomensurabilidade, de tal forma que sempre, após uma revolução, um novo ideal de boa ciência aparece. Ou quando ele diz, ou pelo menos dizia em sua posição inicial, que existe apenas conversão entre adeptos de paradigmas diferentes. Não concordo com isso. Pelo contrário, acredito que entre os paradigmas da filosofia primeira existe uma relação de progresso no nível de radicalizaçáo da reflexão. No início, tínhamos a metafísica ontológica, com uma reflexão sobre as condiçóes de possibilidade de conhecimento verdadeiro. Então tivemos, em Kant, por exemplo, a primazia da reflexão sobre as condiçóes de possibilidade de validade intersubjetiva do conhecimento. Hoje, temos como paradigma da filosofia a questáo de como podemos argumentar com sentido. Pesquisa-se para tentar definir a diferença entre argumentação com e sem sentido. Assim, eu diria que a crítica do significado está hoje no posto da filosofia primeira. Eu diria que hoje não temos metafísica ontológica, nem epistemologia crítica no estilo kantiano. O que temos agora é crítica de significado. Esta é minha idéia de três paradigmas sucessivos da filosofia primeira, que constituem uma seqüência progressiva, em termos de radicalização da reflexão. Isso não é apenas uma seqüência - como Kuhn afirma - entre paradigmas incomensuráveis.

Jesus de Paula Assis é bacharel em Física pelo Instituto de Física (IF) da USP e mestre em Sociologia pela Faculdade de Filosofia, Letras e Ciências Humanas (FFLCH) da USP. Foi pofessor na Unesp, campus de Marlia, entre 1987 e 1988. Depois disso, ingressou na Folha de S. Paulo, onde exerceu os cargos de editor do caderno "ciência" e de repórter especial. Atualmente é aluno de doutorado no departamento de Sociologia da FFLCH-USP. 